\title{
DEVELOPMENT AND IN VITRO EVALUATION OF 5-FLUOROURACIL NANOPARTICLES BY SALTING OUT TECHNIQUE
}

\author{
SAILAJA PB*, JEEVANA JYOTHI B \\ Department of Institute of Pharmaceutical Technology, Sri Padmavati Mahila Visvavidyalayam, Tirupati, Andhra Pradesh, India. \\ Email: jeevanajyothib8@gmail.com
}

Received: 28 January 2020, Revised and Accepted: 26 February 2020

\begin{abstract}
Objectives: At the current miserable state of the prevalence of cancers, there is a need for the development of simple technologies to prepare formulations of anticancer drugs with less economy and investment. Hence, the aim of the present work is to prepare nanoparticles of 5-fluorouracil (5-FU) by simple technique, such as salting out method.
\end{abstract}

Methods: Nanoparticles containing $10 \mathrm{mg}$ of 5-FU were prepared by salting out method using Eudragit-100 as polymer. The prepared nanoparticles were evaluated by particle size, zeta potential, in vitro drug release studies, and drug-excipient interaction studies.

Results: Nanoparticles prepared by salting out methods showed higher dissolution rate for formulation F3 and F5 revealed high percentage release of $98.6 \pm 0.24$ in $60 \mathrm{~min}$ and $86.5 \pm 0.39 \%$ in $120 \mathrm{~min}$. Fourier transform infrared (FTIR) spectra revealed no interaction between drug and excipients used for preparation.

Conclusion: 5-FU nanoparticles can be produced successfully by salting out method using drug to polymer (Eudragit S-100) ratio of 1:3 to possess ideal drug release characteristics and average particle size of $205.1 \mathrm{~nm}$.

Keywords: 5-Fluorouracil, Pancreatic cancer, Nanoparticles, Salting out method, Enhanced dissolution.

(C) 2020 The Authors. Published by Innovare Academic Sciences Pvt Ltd. This is an open access article under the CC BY license (http://creativecommons. org/licenses/by/4. 0/) DOI: http://dx.doi.org/10.22159/ajpcr.2020.v13i4.36967

\section{INTRODUCTION}

At present, cancer is the leading cause of mortality and one of the most difficult global health hazards to tackle [1]. Due to high prevalence of various types of cancers right now, there is a large demand for therapeutics. The prevalence did not spare the people based on their economic and social status. India is ranked one with oral cancer, especially in low-class public. According to the WHO, cancer is the second leading cause of human deaths. Hence, there is a need and demand for the production of formulations of anticancer drugs by economical and simple techniques with optimum quality.

Pancreatic cancer is the ninth more prevalent and challenging to treat. Several formulations are now available for the treatment of pancreatic cancer and 5-fluorouracil (5-FU) is one of the most widely used drugs to treat pancreatic cancer $[2,3]$. It is a sparingly soluble drug with less cellular uptake [4]. Hence, the conversion of the dug in the form of nanoparticles may solve these defects to enhance solubility, leading enhanced cellular uptake and permeability. At this context, formulations of 5-FU can develop using nanotechnology. Especially, nanoparticles as a tool for targeted therapy in cancer treatment have an attention due to higher intracellular uptake compared to microparticles ( $>1 \mathrm{um}$ ) $[5,6]$. The effective delivery of the drug in the epithelium of the blood in human tumors has been according to pore size, which varies from 200 to $600 \mathrm{~nm}$ and the particles should be $<200 \mathrm{~nm}[7-9]$.

Hence, the aim of the present work is the design of nanoparticles of 5-FU by simple method such as salting out technique as this particular method is not so far reported for the production of nanoparticles of 5-FU. This technique may become a promising, simple, and economical process for the production of nanoparticles possessing optimum solubility and drug release characteristics.
Salting out is based on separation of water miscible solvent from aqueous solutions through salting out effect. Polymer and drug are initially dissolved in a solvent which is emulsified into aqueous gel containing salting out agent. This o/w emulsion is diluted with sufficient quantity of water to enhance diffusion of solvent into aqueous phase. Thus inducing the formation of nanospheres. In this method, several manufacturing parameters can be varied including stirring rate, internal/external ratio, concentration of polymers in the organic phase, type of electrolyte, and type of stabilizer in aqueous phase [10].

\section{MATERIALS AND METHODS}

\section{Materials}

5-FU was obtained as a gift sample from Aurobindo Pharma Ltd., Eudragit S-100 and sodium carboxymethyl cellulose (CMC) were purchased from Merck Chemical Company (Mumbai, India), zinc sulfate and ethanol were obtained from Sigma-Aldrich (Mumbai, India), and all other chemicals used in the study are of analytical grade.

\section{Methods}

Preparation of nanoparticles of 5-FU

Nanoparticles of 5-FU were prepared by salting out method [11]. Various trials containing $10 \mathrm{mg}$ of 5-FU were tried and five number of formulations (F1-F5) produced with clear yield are presented in Table 1. During the preparation, 5-FU and Eudragit S-100 were dissolved in ethanol (organic phase). In another beaker, $2 \mathrm{~g}$ of sodium $\mathrm{CMC}$ and $4 \mathrm{~g}$ of zinc sulfate were taken in $20 \mathrm{ml}$ of distilled water and mixed well to dissolve completely (aqueous phase). Organic phase is suddenly poured in to aqueous part under stirring. Stirring is continued for about $3 \mathrm{~h}$ under mechanical stirring for about $1500 \mathrm{rpm}$. After stirring, small quantity of water was added to the dispersion, mixed well, and subjected for vacuum filtration. The filtrate was dried in 
Table 1: Composition of 5-FU nanoparticles

\begin{tabular}{lllll}
\hline Formulation & Drug (mg) & Eudragit S-100 & Sodium CMC (g) & Zinc sulfate (g) \\
\hline F1 & 10 & 10 & 2.0 & 4.0 \\
F2 & 10 & 20 & 2.0 & 4.0 \\
F3 & 10 & 30 & 2.0 & 4.0 \\
F4 & 10 & 40 & 2.0 & 4.0 \\
F5 & 10 & 50 & 2.0 & 4.0 \\
\hline
\end{tabular}

CMC: Carboxymethyl cellulose, 5-FU: 5-Fluorouracil

lyophilizer (Lyodel, JAPAN) for $24 \mathrm{~h}$ and the product was subjected to in vitro evaluation.

\section{In vitro evaluation of nanoparticles of 5-FU}

Prepared formulations, F1-F5, are subjected to in vitro evaluation by particle size determination, zeta potential measurement using Zetasizer, scanning electron microscopy, entrapment efficiency, in vitro dissolution studies, and drug-excipient interaction studies by Fourier transform infrared (FTIR).

\section{Drug content estimation}

Nanoparticles equivalent to containing $10 \mathrm{mg}$ of 5 -FU were weighed and taken in $100 \mathrm{ml}$ beaker containing $50 \mathrm{ml}$ of ethanol. The solution was stirred at $1000 \mathrm{rpm}$ for $4 \mathrm{~h}$ in magnetic stirrer. The resultant solution was filtered and estimated for drug content using ultraviolet (UV)--visible spectrophotometer at $\lambda_{\max }$ at $265 \mathrm{~nm}$.

In vitro dissolution studies

The drug release studies were carried out using USP XX1 dissolution testing type-II apparatus (Electrolab, INDIA) for prepared formulations F1-F5 and for pure drug. The dissolution medium was $\mathrm{pH} 6.8$ phosphate buffer maintained at temperature of $37 \pm 1^{\circ} \mathrm{C}$ with rotating speed of $100 \mathrm{rpm}$. At predetermined time intervals, aliquot samples were withdrawn and diluted wherever necessary and analyzed for drug content by UV spectrophotometer (Systronics, INDIA) $\lambda_{\max }$ at $265 \mathrm{~nm}$. The volume withdrawn was replaced with fresh dissolution medium maintained at same temperature.

Particle size determination and zeta potential measurement

Particle size and zeta potential of formulations F3 and F5 with enhanced $\%$ drug release values among all prepared formulations were determined using Zetasizer (Horiba).

\section{FTIR analysis}

The FTIR spectra of the samples were recorded for formulation F3 and for pure 5-FU using a FTIR spectrometer (Bruker, JAPAN). A small quantity of nanoparticles was mixed with $200 \mathrm{mg}$ of $\mathrm{KBr}$ and compressed to form pellets. These pellets were scanned in transmission mode in the spectral region $4000-400 \mathrm{~cm}^{-1}$ using a resolution of $4 \mathrm{~cm}^{-1}$ and 32 coadded scans.

\section{RESULTS AND DISCUSSION}

In the present work, five formulations, F1-F5, were tried to produce nanoparticles of 5-FU by salting out method. This method is based on the separation of water miscible solvent from aqueous solution through salting out effect. The concentration of zinc sulfate will prevent the miscibility of ethanol into aqueous medium on mechanical agitation of this system, emulsion is formed. The formed emulation droplet size controlled by salting out agent. The increasing concentration of salting agent reduced the size of particles.

\section{Characterization of the Nanoparticles}

Drug content

The results of percentage drug content of formulations are presented in Table 2. It was observed that as the drug to polymer concentration
Table 2: Percentage drug content

\begin{tabular}{ll}
\hline Formulation code & Percentage drug content $(\mathbf{n}=\mathbf{3} \pm$ SD) \\
\hline F1 & $96.5 \pm 0.61$ \\
F2 & $97.6 \pm 0.32$ \\
F3 & $99.7 \pm 0.55$ \\
F4 & $98.9 \pm 0.68$ \\
F5 & $98.5 \pm 0.65$ \\
\hline
\end{tabular}

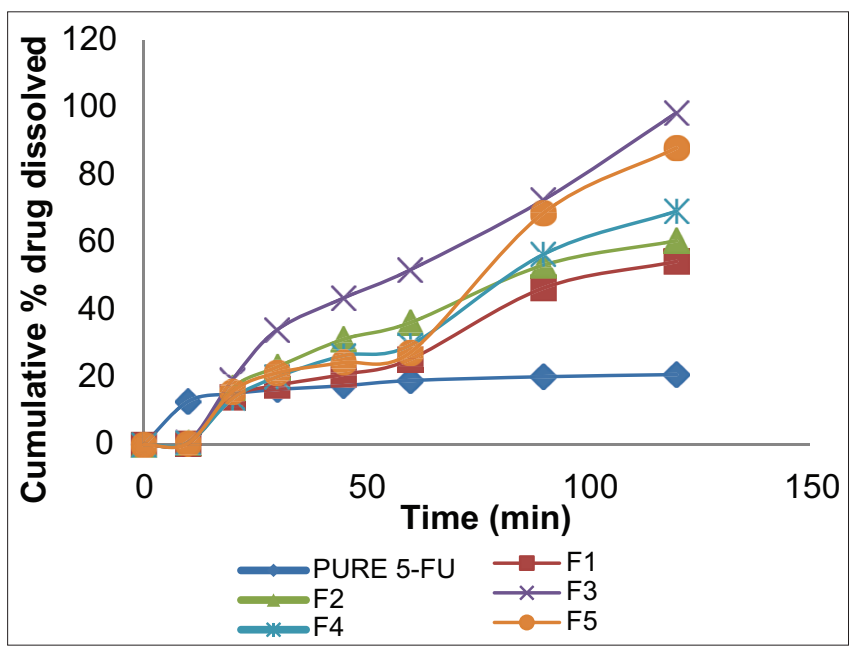

Fig. 1: Dissolution curves of pure 5-fluorouracil and prepared nanoparticles

increases from F3 to F5, drug content was found to be acceptable with the range of $96.5 \% \pm 0.61-99.7 \% \pm 0.55$.

\section{In vitro drug release studies}

Cellular uptake of anticancer drug delivery systems plays a crucial role to elicit effective action against the cancerous tissues. Hence, as an indirect assessment, the prepared formulations were assessed for in vitro drug release studies. The results of drug releasing studies of F1-F5 and pure 5-FU are presented in Table 3 and Fig. 1. From the data, it is observed that there is enhanced \% drug release from all the prepared formulations compared to pure drug release. Among all, formulations, F3 (98.5\%) and F5 (88.07\%), evidenced high \% drug release values.

\section{Particle size and zeta potential}

The particle size of prepared nanoparticles of formulations F3 and F4 is determined as the drug release is high from them. The scan copies indicating particle and zeta potential obtained from Zetasizer are presented in Figs. 2 and 3 and the values are shown in Table 4. The mean particle size of formulation F3 is $205.1 \mathrm{~nm}$ and formulation F5 is $231.6 \mathrm{~nm}$. This indicates that the present method used for preparing nanoparticles is successful in producing the yield in nanosize range. Zeta potential influences the stability of nanoparticles. Extremely negative values of zeta potential indicate large repulsive forces showing the stability of prepared nanoparticles. 


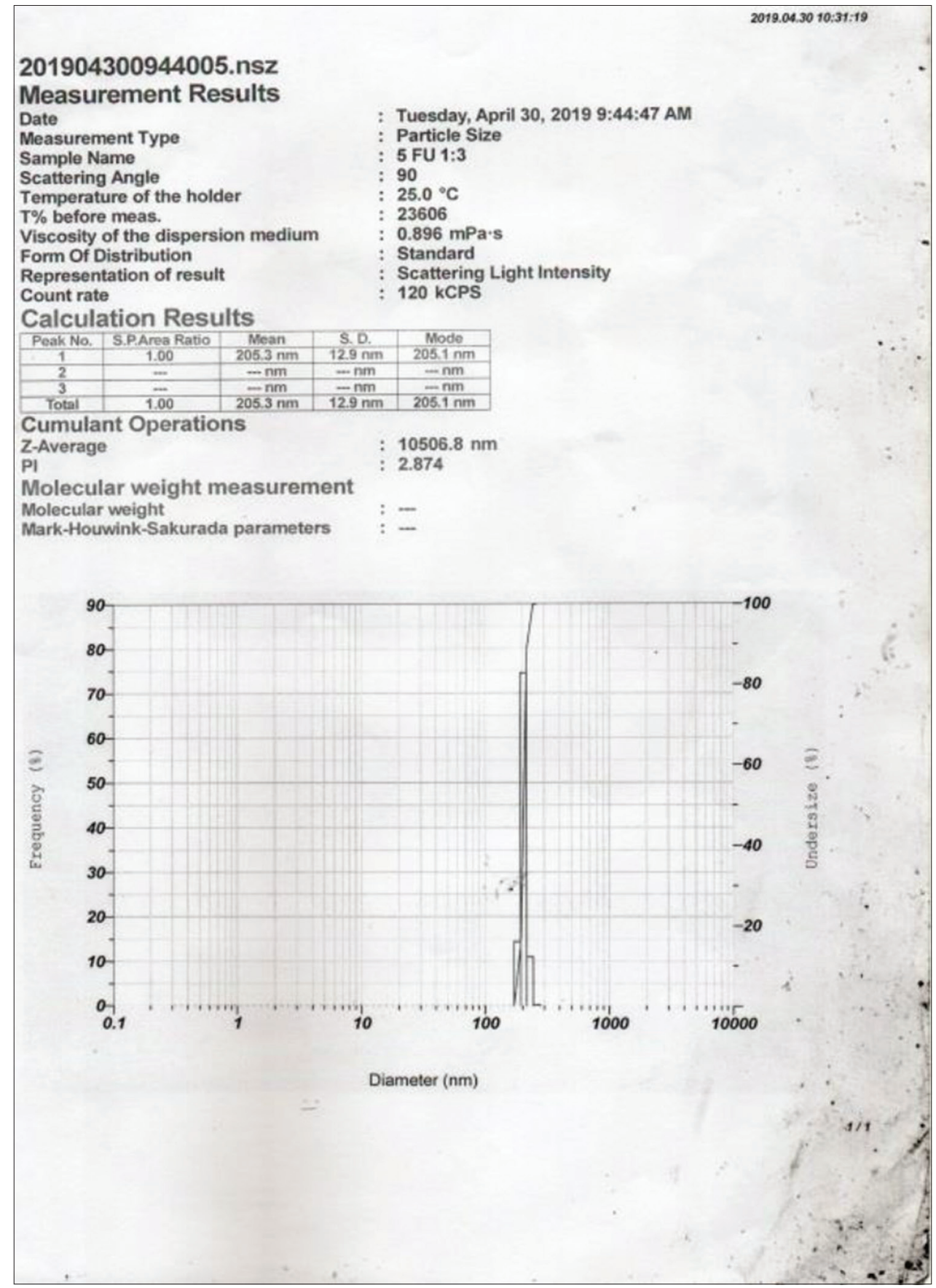

Fig. 2: Particle size of F3

Table 3: Dissolution data of pure 5-FU and prepared nanoparticles of 5-FU formulations, F1-F5

\begin{tabular}{llllll}
\hline Time (min) & Pure 5-FU & F1 & F2 & F3 & F5 \\
\hline 10 & $12.83 \pm 0.11$ & $0.37 \pm 0.09$ & $0.58 \pm 0.04$ & $0.855 \pm 0.11$ & $0.62 \pm 0.07$ \\
20 & $15.10 \pm 0.58$ & $14.02 \pm 0.5$ & $16.85 \pm 0.19$ & $19.30 \pm 0.22$ & $13.67 \pm 0.63$ \\
30 & $16.37 \pm 0.38$ & $17.60 \pm 0.24$ & $23.02 \pm 0.21$ & $34.02 \pm 0.75$ & $20.08 \pm 0.11$ \\
45 & $17.5 \pm 0.42$ & $20.87 \pm 0.15$ & $31.28 \pm 0.27$ & $43.50 \pm 0.42$ & $26.45 \pm 0.41$ \\
60 & $19.02 \pm 0.13$ & $25.32 \pm 0.19$ & $36.20 \pm 0.22$ & $51.85 \pm 0.51$ & $29.50 \pm 0.89$ \\
90 & $20.16 \pm 0.26$ & $46.45 \pm 0.28$ & $53.25 \pm 0.37$ & $72.6 \pm 0.30$ & $56.45 \pm 0.21$ \\
120 & $20.80 \pm 0.44$ & $54.35 \pm 0.48$ & $60.51 \pm 0.33$ & $98.5 \pm 0.23$ & $69.3 \pm 0.30$ \\
\hline
\end{tabular}

5-FU: 5-Fluorouracil

Drug-excipient interaction studies by FTIR

The FIIR spectra of formulation F3 and pure 5-FU are given in Figs. 4 and 5 , and the absorption peaks are shown in Table 5. Pure 5-FU showed
$\mathrm{N}-\mathrm{H}$ stretch at $3134.7, \mathrm{C}-\mathrm{H} 17274$ at $\mathrm{c}=\mathrm{o}$ stretch at 1699.13 due to and $\mathrm{C}-\mathrm{N}$ stretch at 1248.75 . All these peaks are also present in spectrum of prepared formulation with slight change. Hence, it is considered that 


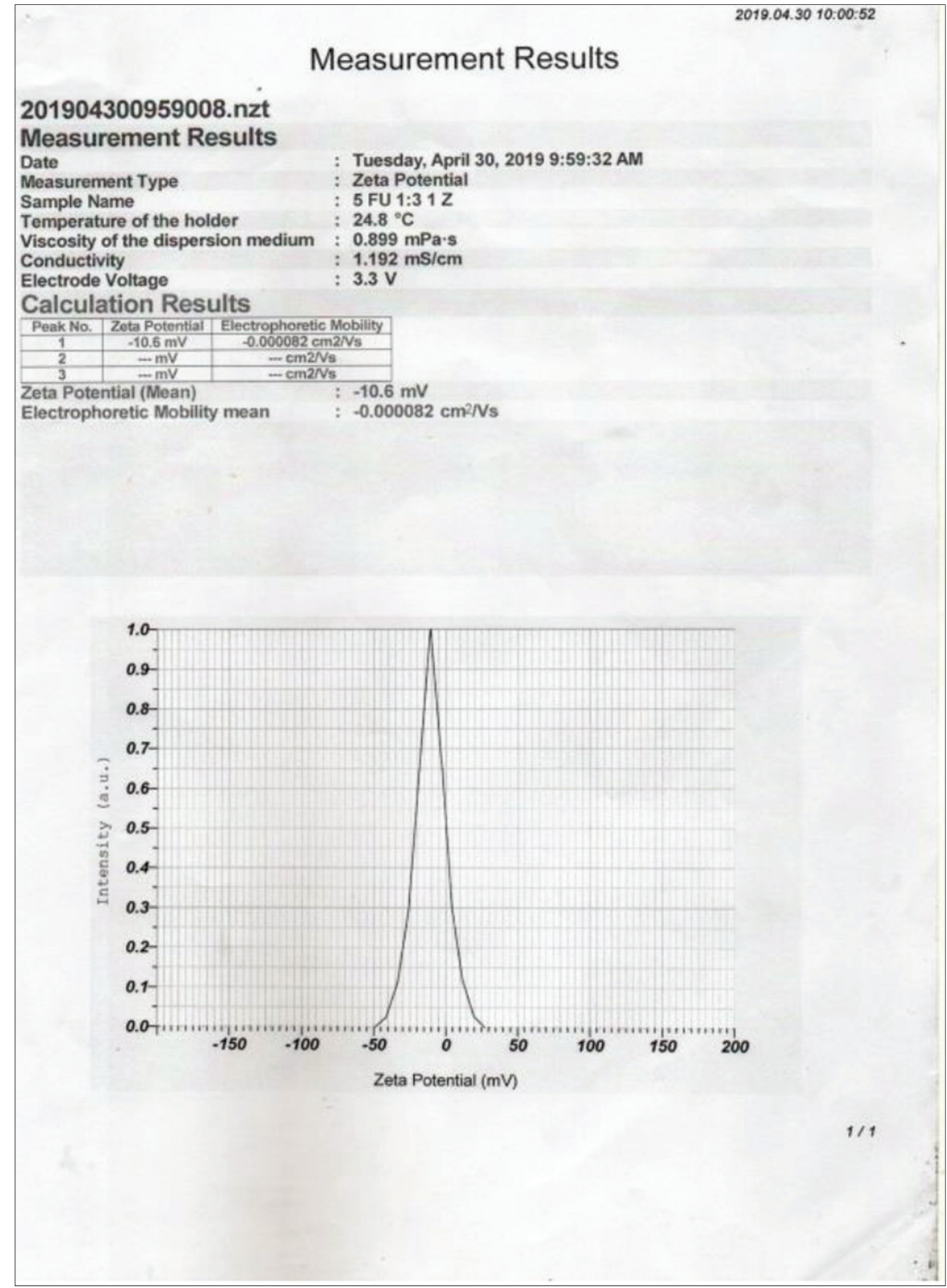

Fig. 3: Zeta potential of F3

Table 4: Particle size and zeta potential determination

\begin{tabular}{lll}
\hline Formulation code & Particle size $(\mathbf{n m})$ & Zeta potential (my) \\
\hline F3 & 205.1 & -10.6 \\
F5 & 231.6 & -2.2 \\
\hline
\end{tabular}

there is no interaction between 5-FU and the excipients used to prepare nanoparticles.

Drug release kinetics

Drug release kinetics of promising formulation F3 was assessed by zero-order, first-order, Higuchi, and Korsmeyer-Peppas (k-p) mechanisms and the relevant plots are shown in Fig. 6 and the data
Table 5: FTIR spectra of prepared nanoparticles

\begin{tabular}{lll}
\hline $\begin{array}{l}\text { Literature } \\
\text { revealed }\end{array}$ & $\begin{array}{l}\text { Absorption spectra of } \\
\text { pure drug 5-FU }\end{array}$ & Formulation 1:5 \\
\hline $\mathrm{N}-\mathrm{H}$ & 3134.7 & 3208 \\
$\mathrm{C}-\mathrm{H}$ & 1727 & 1680 \\
$\mathrm{C}=\mathrm{O}$ & 1699.13 & 1587 \\
$\mathrm{C}-\mathrm{N}$ & 1248.75 & 1033 \\
\hline
\end{tabular}

FTIR: Fourier transform infrared, 5-FU: 5-Fluorouracil

of copies given plots. It is evident that regression values for zero order were more linear (0.976) compared to the first order (0.879), indicating that the release of drug is dose independent. KorsmeyerPeppas plot (0.903) with $\mathrm{n}=0.862$ which falling in between 0.45 


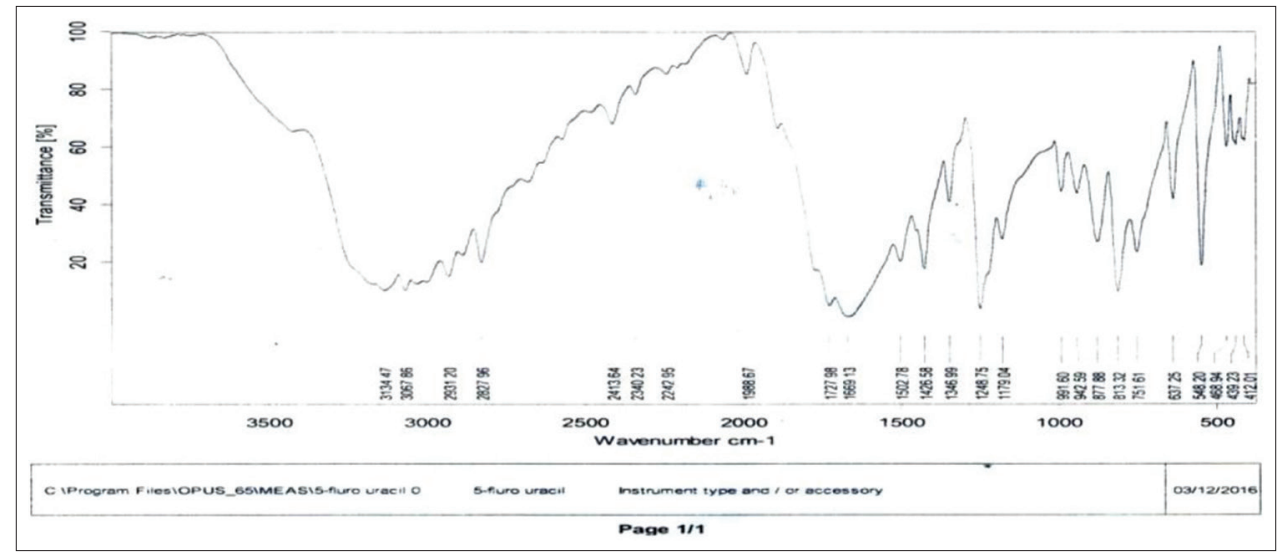

Fig. 4: Fourier transform infrared spectrum of pure drug 5-fluorouracil

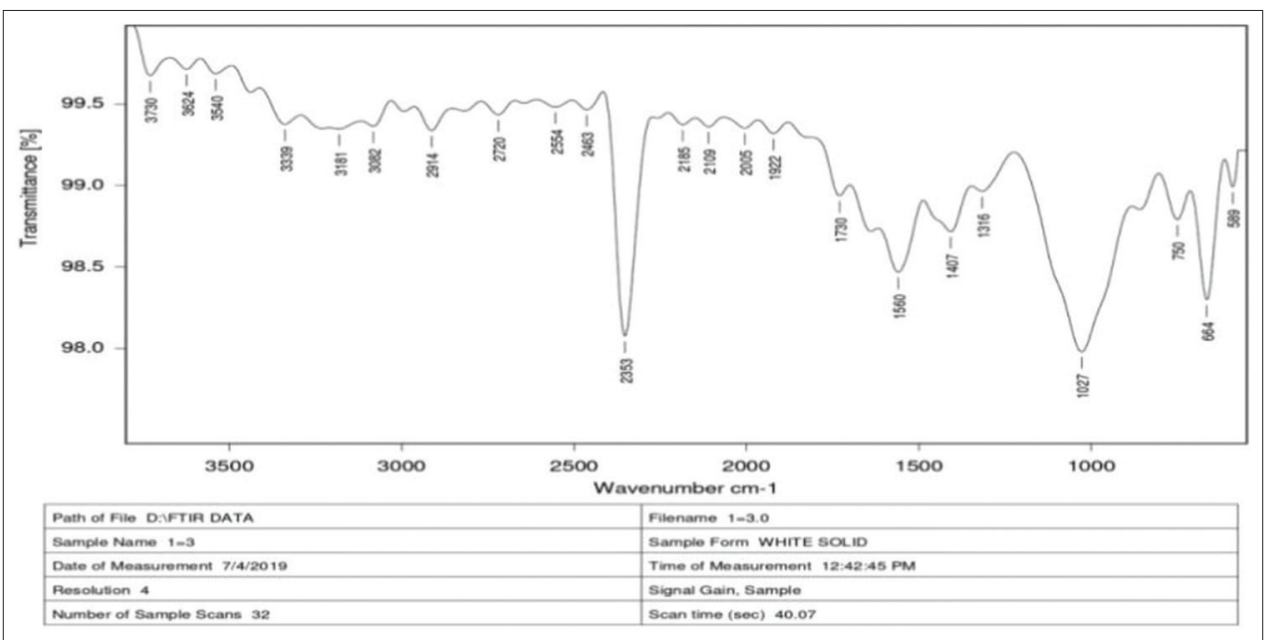

Fig. 5: Fourier transform infrared spectrum of formulation F3
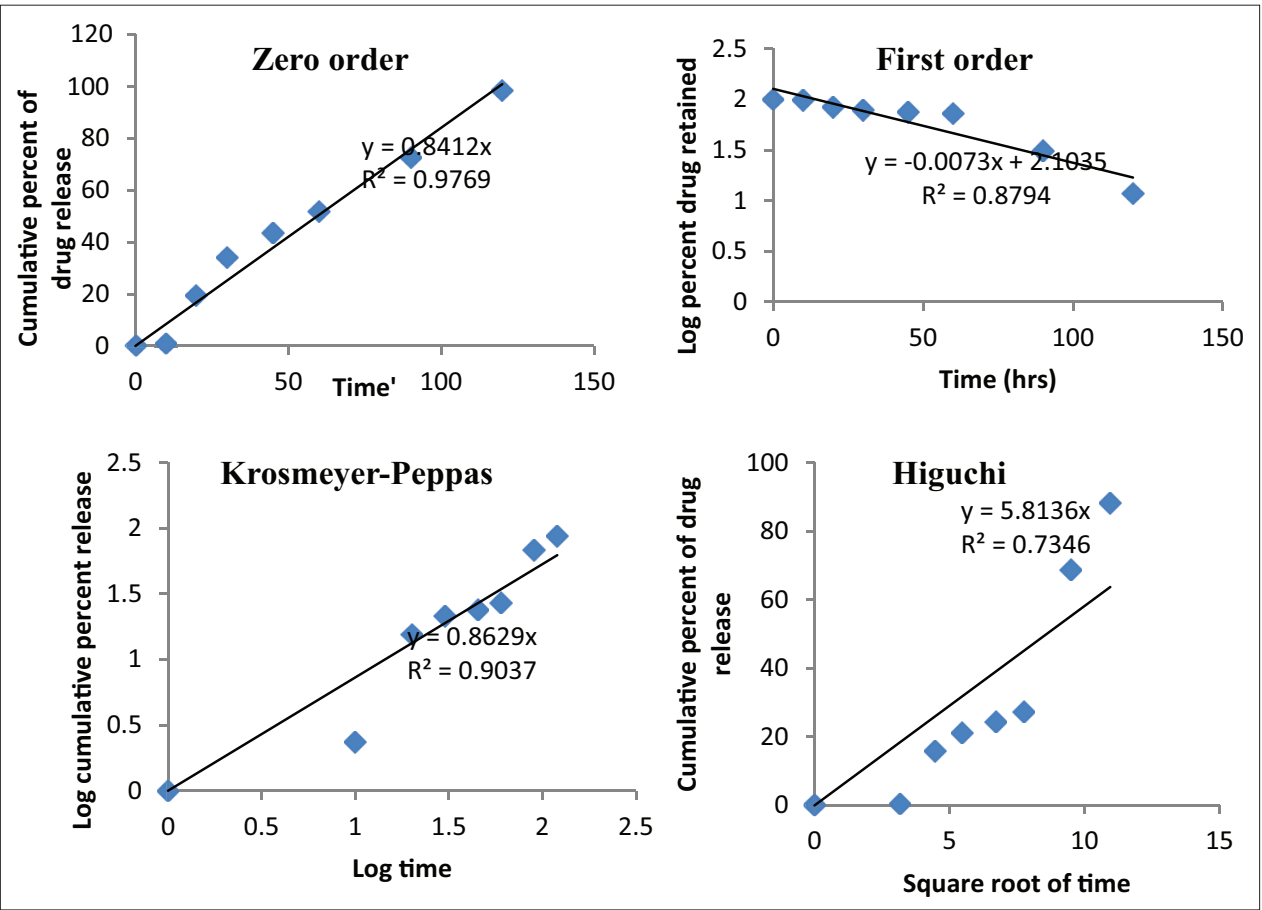

Fig. 6: Kinetic plots of formulation F3 
Table 6: Data of drug release kinetics plots

\begin{tabular}{|c|c|c|c|c|c|c|c|}
\hline Time (min) & $\begin{array}{l}\% \text { cumulative drug } \\
\text { release }\end{array}$ & $\begin{array}{l}\text { Log\% cumulative } \\
\text { drug release }\end{array}$ & $\begin{array}{l}\% \text { drug } \\
\text { retained }\end{array}$ & $\begin{array}{l}\text { Log } \% \text { drug } \\
\text { retained }\end{array}$ & $\log T$ & $\sqrt{\mathrm{T}}$ & $\sqrt[3]{\mathrm{T}}$ \\
\hline 0 & 0 & 0 & 100 & 2 & 0 & 0 & 0 \\
\hline 10 & 0.855 & 0.068 & 99.145 & 1.99 & 1 & 3.162 & 2.154 \\
\hline 20 & 19.30 & 1.28 & 80.7 & 1.90 & 1.301 & 4.472 & 2.714 \\
\hline 30 & 34.02 & 1.53 & 65.98 & 1.81 & 1.477 & 5.477 & 3.107 \\
\hline 45 & 43.50 & 1.63 & 56.5 & 1.752 & 1.653 & 6.708 & 3.556 \\
\hline 60 & 51.85 & 1.714 & 48.15 & 1.682 & 1.778 & 7.745 & 3.914 \\
\hline 120 & 98.5 & 1.99 & 1.5 & 0.176 & 2.079 & 10.95 & 4.932 \\
\hline
\end{tabular}

and 0.89 evidenced that the release follows non-Fickian diffusioncontrolled mechanism.

\section{CONCLUSION}

5-FU nanoparticles were successfully produced by salting out method using drug-to-polymer (Eudragit S-100) ratio of 1:3 to possess ideal drug release characteristics of $72.6 \%$ in $90 \mathrm{~min}$ and $98.5 \%$ in $120 \mathrm{~min}$ with average particle size $205.1 \mathrm{~nm}$.

\section{Scope}

5-FU can be produced as nanoparticles by salting out method which on large scale after pilot plant scale-up studies which may become a promising economical method on the part of the industrial production.

\section{ACKNOWLEDGMENTS}

The authors acknowledge their gratitude to DST-CURIE Facilities of Sri Padmavati Mahila Visvavidyalayam, Tirupati, for providing FTIR, differential scanning calorimetry, and dissolution testing apparatus as and when required for the study.

\section{AUTHORS' CONTRIBUTIONS}

Jeevana Jyothi B has designed the plan of present work and responsible for this novel work and preparation of manuscript. Ms. Sailaja PB has performed the experiments involved in the present research work.

\section{CONFLICTS OF INTEREST}

The authors have no conflicts of interest.

\section{AUTHORS' FUNDING}

The present research work did not receive any financial assistance from funding agencies.

\section{REFERENCES}

1. Tran S, DeGiovanni P, Piel B, Rai P. Cancer nanomedicine: A review of recent success in drug delivery. Clin Transl Med 2017;6:44.

2. Nasr M, Ghorab MK, Abdlazem A. In vitro and in vivo evaluation of cubosomes containing 5-fluorouracil for liver targeting. Acta Pharm Sin B 2015;5:79-88.

3. Tawfik E. Prolonged exposure of colon cancer cells to 5-fluorouracil nanoparticles improves its anticancer activity. Saudi Pharma J 2017;25:206-13.

4. Kavitha K, Rao SA, Nalini CN. An investigation on enhancement of solubility of 5 flourouracil by applying complexation techniquecharacterization, dissolution and molecular-modelling studies. J Appl Pharm Sci 2013;3:162-6.

5. Tummala S. Formulation and characterization of 5-fluorouracil enteric coated nanoparticles for sustained and localized release in treating colorectal cancer. Saudi Pharm J 2015;23:308-14.

6. Pridgen EM, Langer R, Farokhzad OC. Biodegradable, polymeric nanoparticle delivery systems for cancer therapy. Nanomedicine (Lond) 2007;2:669-80.

7. Patra JK, Das G, Fraceto LF, Campos EV, Rodriguez-Torres MD, Acosta-Torres LS, et al. Nano based drug delivery systems: Recent developments and future prospects. J Nanobiotechnology 2018;16:71.

8. Patel M, Patel NV, Patel TB. Design and development of rilpivirine nanoparticle containing chitosan using ionic gelation method for HIV infections. Int J Pharm Pharm Sci 2020;12:113-8.

9. Gopi G, Kannan K. Formulation development and optimization of nateglinide-loaded ethyl cellulose nanoparticles by Box-Behnken design. Int J Pharm Pharm Sci 2015;7:310-5.

10. Allemann E, Gurny R. Drug-loaded nanopratcles-preparation methods and drug targeting issues. Eur J Pharm Biopharm 1993; 39:173-91.

11. Galindo-Rodriguez S, Allemann E, Fessi H, Doelker E. Physicochemical parameters associated with nanoparticle formation in the salting-out, emulsification-diffusion, and nanoprecipitation methods. Pharm Res 2004;21:1428-39. 